Journal of Animal

Ecology 2007

76, 568-579

\title{
Changes in landscape composition influence the decline of a threatened woodland caribou population
}

\author{
HEIKO U. WITTMER*†, BRUCE N. MCLELLAN†, ROBERT SERROUYA§ \\ and CLAYTON D. APPS \\ *Agroecology, Faculty of Land and Food Systems, University of British Columbia, 2357 Main Mall, Vancouver, \\ British Columbia, V6T 1Z4, Canada; $†$ Ecology Group, Institute of Natural Resources, Massey University, Private \\ Bag 11222, Palmerston North, New Zealand; \$British Columbia Ministry of Forests and Range, RPO 3, PO Box \\ 9158, Revelstoke, British Columbia, V0E3K0, Canada; §Revelstoke Mountain Caribou Research Project, RPO3, PO \\ Box 9158, Revelstoke, British Columbia, V0E3K0, Canada; and Aspen Wildlife Research, 2708 Cochrane RoadNW, \\ Calgary, Alberta, T2M 4H9, Canada
}

\section{Summary}

1. Large-scale habitat loss is frequently identified with loss of biodiversity, but examples of the direct effect of habitat alterations on changes in vital rates remain rare. Quantifying and understanding the relationship between habitat composition and changes in vital rates, however, is essential for the development of effective conservation strategies.

2. It has been suggested that the decline of woodland caribou Rangifer tarandus caribou populations in North America is precipitated by timber harvesting that creates landscapes of early seral forests. Such habitat changes have altered the predator-prey system resulting in asymmetric predation, where predators are maintained by alternative prey (i.e. apparent competition). However, a direct link between habitat condition and caribou population declines has not been documented.

3. We estimated survival probabilities for the threatened arboreal lichen-feeding ecotype of woodland caribou in British Columbia, Canada, at two different spatial scales. At the broader scale, observed variation in adult female survival rates among 10 distinct populations (range $=0.67-0.93$ ) was best explained by variation in the amount of early seral stands within population ranges and population density. At the finer scale, home ranges of caribou killed by predators had lower proportions of old forest and more mid-aged forest as compared with multi-annual home ranges where caribou were alive. 4. These results are consistent with predictions from the apparent competition hypothesis and quantify direct fitness consequences for caribou following habitat alterations. We conclude that apparent competition can cause rapid population declines and even extinction where changes in species composition occur following large scale habitat change.

Key-words: apparent competition, caribou, extirpation, habitat loss, population dynamics, predation, survival analysis.

Journal of Animal Ecology (2007) 76, 568-579

doi: $10.1111 / \mathrm{j} .1365-2656.2007 .01220 . \mathrm{x}$

\section{Introduction}

Habitat loss is a major cause of extinction (Caughley 1994; Sih, Jonsson \& Luikart 2000; Fahrig 2003).

(C) 2007 The Authors. Journal compilation (C) 2007 British Ecological Society
Correspondence: Heiko U. Wittmer, Wildlife, Fish \& Conservation Biology, University of California, One Shields Avenue, Davis, CA 95616, USA. Tel.: +1(530)754 7640. E-mail: huwittmer@ucdavis.edu
The effect of habitat loss has been particularly well documented in the decline of species associated with late-successional forests such as the northern spotted owl Strix occidentalis caurina (Merriam) in western North America (e.g. Franklin et al. 2000; Noon \& Blakesley 2006). Although maintaining old forests in protected areas will help conserve many species, protected areas are generally too small for wide-ranging and migratory species (Carroll, Noss \& Paquet 2001; 
569

Landscape changes and decline of caribou

(C) 2007 The Authors. Journal compilation (C) 2007 British Ecological Society, Journal of Animal Ecology, 76, 568-579
Berger 2004), and land-management decisions made outside protected areas usually determine their fate. Natural resources, and in particular old forests, are of great economic importance and thus the trade-off between conservation and economic value is the basis for many land-use decisions. Quantifying the relationship and understanding the mechanism between habitat composition and changes in vital rates for the species of concern is therefore required to make appropriate decisions.

The relationship between habitat composition and vital rates of wide-ranging species has rarely been quantified due to the challenge of conducting large-scale manipulative research. However, vital rates influencing population viability vary spatially and an inductive comparison among populations can be insightful. At relatively fine scales, such comparisons among population units have been successful in linking variation in vital rates to habitat conditions (e.g. Coulson et al. 1999; Franklin et al. 2000; Pettorelli et al. 2005).

The obligate arboreal lichen-feeding ecotype of woodland caribou Rangifer tarandus caribou (Gmelin) (referred to throughout the manuscript by their local name of (mountain caribou') in British Columbia, Canada, is a wide-ranging species that is dependent on attributes of old forests for several life-history requirements, including the arboreal lichen they eat during winter (Rominger, Robins \& Evans 1996; Terry, McLellan \& Watts 2000). Over the past decade, the abundance of these caribou has declined by approximately $8 \%$ per year across their distribution with individual populations decreasing at up to $20 \%$ per year (Wittmer et al. 2005a). By 2004, the remaining caribou were fragmented into 18 largely isolated populations varying in size from $<10$ to $>400$ individuals and totalling $<1600$ individuals. As a consequence of the increased risk associated with small, declining and fragmented populations, mountain caribou are categorized as 'threatened' with extinction in Canada (COSEWIC 2002) and 'endangered' in the USA (US Fish and Wildlife Service 1994).

It has been suggested that the decline of woodland caribou across North America, including that of mountain caribou, has been precipitated by timber harvesting that creates landscapes of early seral stage vegetative communities (Rettie \& Messier 1998; Schaefer 2003; Wittmer et al. 2005a). These early successional communities resulted in population increases of other ungulates such as moose Alces alces (Linnaeus) (Rempel et al. 1997), which in turn support higher densities of predators (Schwartz \& Franzmann 1991; Ballard et al. 2000). This relationship has led to the hypothesis that the decline of woodland caribou is based on an indirect interaction between caribou and landscape composition through other prey species and their shared predators (Bergerud \& Elliot 1986; Seip 1992; Wittmer, Sinclair \& McLellan 2005b). Such an indirect interaction between prey populations is commonly referred to as apparent competition (Holt
\& Lawton 1994). While studies generally show that predation is the primary cause of adult mortality in woodland caribou (Stuart-Smith et al. 1997; Rettie \& Messier 1998; Wittmer et al. 2005a), the relationship between habitat composition, caribou vital rates and population decline consistent with the apparent competition hypothesis has not been quantified.

Adult female survival is the parameter that most strongly influences population declines of mountain caribou (Wittmer et al. 2005a). In this paper we evaluate the importance of several environmental factors, including those consistent with the apparent competition hypothesis, on the survival of adult female caribou. Our analysis covers two spatial scales. At the broader, population scale, we consider the variability of habitat composition among caribou populations. At the finer, home range scale, we consider the variability of habitat composition among the home ranges of caribou killed by predators. Our analyses highlight the importance of quantifying the relationship between vital rates and limiting factors causing population decline and should support land-use decisions for effective mountain caribou conservation, particularly outside of protected areas.

\section{Methods}

\section{STUDY AREA}

Mountain caribou are the southernmost remaining caribou in North America. Their distribution currently covers $>50000 \mathrm{~km}^{2}$ from just south of the Canada/ USA border at $49^{\circ} \mathrm{N}$ latitude to north-east of Prince George, British Columbia, Canada, at approximately $55^{\circ} \mathrm{N}$ latitude (Fig. 1). Topography is variable across the distribution of caribou with elevation ranging from $400 \mathrm{~m}$ to $>3500 \mathrm{~m}$. The climate is influenced by Pacific air masses resulting in high annual precipitation, most of which falls as snow during winter. Owing to wet conditions and infrequent wildfires, forests in the study area are naturally dominated by old stands (Meidinger \& Pojar 1991) that are subject to different intensities of forest harvesting. Wittmer et al. (2005a) provide a detailed description of the vegetative communities across the range of mountain caribou in British Columbia.

Mountain caribou in southern British Columbia are part of a multiprey, multipredator system. The distribution of other species is determined by topography, climate and habitat characteristics. In general, mountain goats Oreamnos americanus (de Blainville) and mule deer Odocoileus hemionus (Rafinesque) are found across the distribution of caribou populations. Moose are also found across the distribution of the caribou populations, but densities are greater in the northern and central portions. Although some moose were present in portions of the study area, their numbers and distribution have greatly expanded since the early 1900s (Spalding 1990). Elk Cervus elaphus (Linnaeus) and white-tailed deer Odocoileus virginianus (Zimmermann) are more abundant in southern areas, and their distribution has 


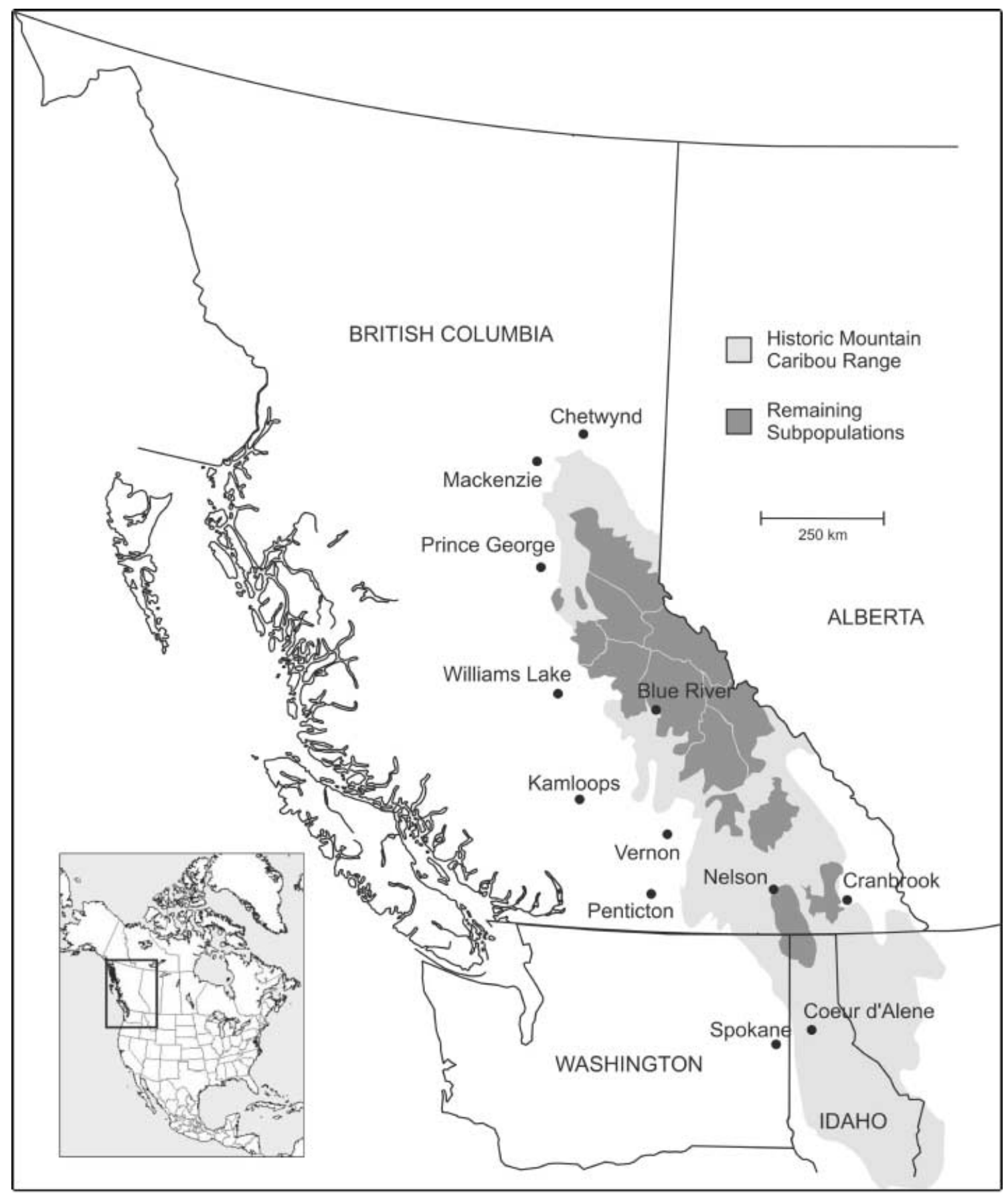

Fig. 1. Approximate current and historic range of mountain caribou in British Columbia, Canada.

(C) 2007 The Authors. Journal compilation C) 2007 British Ecological Society, Journal of Animal Ecology, 76,

568-579 also increased over the past several decades (Shackleton 1999). Common predators across the distribution of caribou include grizzly bears Ursus arctos (Linnaeus), black bears Ursus americanus (Pallas) and wolverine Gulo gulo (Linnaeus), whereas wolves Canis lupus (Linnaeus) are more abundant in the north and cougar Puma concolor (Linnaeus) are more abundant in the south.

\section{CARIBOU CAPTURE AND MONITORING}

From 1984 to 2004, we captured 338 adult ( $\geq 2$ years) female caribou and fitted them with mortality motionsensitive radiotelemetry collars to obtain location and survival data. Capture and marking procedures are described by Wittmer et al. (2005a). Caribou were relocated from fixed-wing aircraft at 1-2-week intervals. Locations were plotted on aerial photographs or topographic maps and coordinates of each animal were recorded to the nearest $100 \mathrm{~m}$. Individual caribou were on average relocated 53.08 ( $\pm 44 \cdot 56)$ times and were monitored for up to 10 consecutive years (mean = $2 \cdot 72 \pm 1 \cdot 10$ years).

When the signal from a motion-sensitive radiocollar indicated a stationary collar, the site was investigated as soon as possible to confirm whether the caribou had died or dropped its collar. A total of 
571

Landscape changes and decline of

caribou
141 female caribou were found to have died and 68\% of mortalities with known cause were attributed to predation (Wittmer et al. 2005a).

\section{COVARIATES WITH SURVIVAL}

Wittmer et al. (2005a) estimated adult survival rates of female mountain caribou in our study area using a staggered entry Kaplan-Meier procedure (Pollock et al. 1989). They found large variation in annual survival rates among populations (range $=0 \cdot 55-0 \cdot 96$ ) and demonstrated that the variation in female survival was largely responsible for the observed variation in population growth rates $(\lambda)$ (range $=0 \cdot 82-1 \cdot 03$ ). We evaluated covariates potentially affecting adult survival at two scales: within distinct populations and within individual home ranges.

\section{Habitat covariates}

We selected habitat covariates based on the hypothesis that caribou population declines are related to the conversion of old forests to young forests (Rettie \& Messier 1998). At both spatial scales, we estimated the proportion of forests within different age classes and that of nonforested habitat above the treeline (Table 1). In addition to age, the configuration of forest stands may also be important for caribou, particularly where forests have become increasingly fragmented through harvest. Within mountain caribou range, most forest harvesting has occurred over the past 30-40 years and has targeted old stands. Therefore, we restricted our estimates of fragmentation indices to forest stands of age $1-40$ years and age $>140$ years. Forest stands that are 40-100 years predominantly originated from wildfires, although the proportion of these fires that were naturally ignited or were set by early settlers and mineral prospectors is not known. We extracted all habitat covariates from $1: 20000$ digital forest inventory planning files (Resource Inventory Branch 1995) rasterized to $250 \mathrm{~m}$ resolution. Forest age data were updated to the year 2000 and are assumed to reflect forest composition over the sampling period.

\section{Climate covariates}

In contrast to other woodland caribou in North America, mountain caribou depend almost exclusively on long-strand arboreal lichen during winter (Bryoria spp. and Alectoria sarmentosa) (Rominger \& Oldemeyer 1989; Rominger et al. 1996; Terry et al. 2000). The deep snow pack of generally $1-5 \mathrm{~m}$ in the study area buries all terrestrial food but caribou walk on top of the deep snow to access lichen in the forest canopy. Arboreal lichen does not grow lower on trees than the maximum snow accumulation, so large interannual variation in snowpack may result in too little snow accumulation in some years for caribou to reach lichen in the lower canopy (Goward 1998).

We explored the effects of among-year variability in snow depth on survival, using variation in annual snow depth as an indicator of winter severity. This approach is consistent with an among-year study approach of climatic variation described by Rotenberry \& Wiens (1991). The height of snow (cm) was measured on the first day of each month from January to April at measurement stations maintained by the Ministry of Sustainable Resource Management (2004). Measurement stations ranged in elevation from $1520 \mathrm{~m}$ to $2010 \mathrm{~m}$ and we assumed that snow data were representative of conditions experienced by caribou in distinct populations on high elevation late winter ranges. For each caribou population, we then calculated the average yearly snow accumulation during this period (i.e. late winter). Finally, we calculated the coefficient of variation (Zar 1999) in snow accumulation among years.

\section{Population density}

The decline of caribou in our area has been correlated with population density, with smaller populations declining at faster rates than larger ones (Wittmer et al. 2005b). The inverse density dependence or Allee effect has been hypothesized to be a consequence of high predation rates where caribou are secondary prey to a predator population that relies on other primary prey. We evaluated the relationship between population density

Table 1. Covariates used to explain variability in survival of female adult mountain caribou at both the population and home range scales in British Columbia, Canada

Covariates Definition

Amount of habitat

(C) 2007 The Authors Journal compilation (C) 2007 British Ecological Society, Journal of Animal Ecology, 76, $568-579$

Climate variable*

\footnotetext{
*Population scale only.
}

Proportion of early seral forest habitat age $1-40$ years (FOR 1-40) Proportion of mid-seral forest habitat age 40-100 years (FOR40-100) Proportion of mid-seral forest habitat age 100-140 years (FOR100-140) Proportion of late-seral forest habitat age > 140 years (FOR140) Proportion of nonforested (alpine) habitat (NONFOR)

Distribution of habitat Edge density around forest habitat age $1-40$ years (ED1-40) Mean patch size forest habitat age 1-40 years (MPS1-40) Mean patch size forest habitat age $>140$ years (MPS140) Population density* Coefficient of variation average yearly snow accumulation (Jan-Apr) (SNOW) Population density within population range (DEN) 


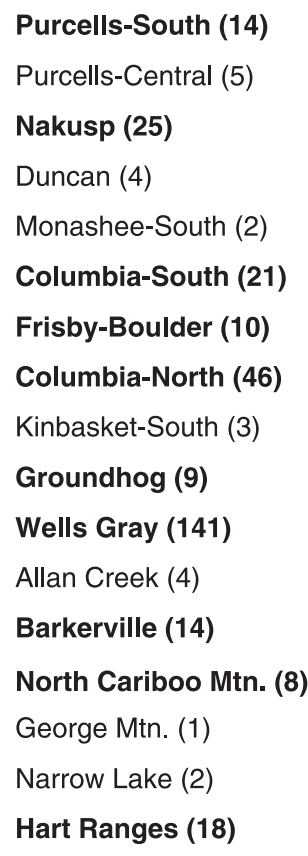

Duncan (4)
Monashee-South (2)
Columbia-South (21)
Frisby-Boulder (10)
Columbia-North (46)
Kinbasket-South (3)
Groundhog (9)
Wells Gray (141)
Allan Creek (4)
Barkerville (14)
North Cariboo Mtn. (8)
George Mtn. (1)
Narrow Lake (2)
Hart Ranges (18)

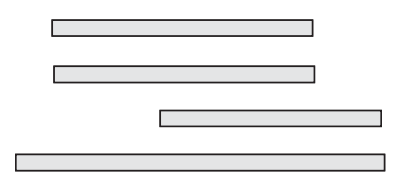

Fig. 2. Temporal distribution of telemetry data of mountain caribou by identified population (number of collared females) in British Columbia, Canada.

and adult female survival, using density estimates derived by dividing each current population estimate by its associated range size.

\section{MODELLING THE EFFECTS OF COVARIATES ON ADULT SURVIVAL}

\section{Population scale}

At the population scale, we estimated annual adult survival probabilities $(\phi)$ using known-fate markrecapture models in program MARK (White \& Burnham 1999). We estimated annual survival for a year that began on 21 May, the approximate start of the calving season (Wittmer et al. 2005a). As caribou were captured in March, this approach likely eliminated potential effects of mortalities associated with capture. Individuals were recorded as alive or dead within the year, with multiple resightings of individuals equating to single encounters. To reduce the effects of small sample sizes (sensu Wittmer et al. 2005a), we only included populations monitored for at least three complete years with at least four caribou collared at the start of each year (Fig. 2). A total of 67 years from 10 of the identified populations met these requirements.

At the population scale, covariates with survival (C) 2007 The Authors. Journal compilation (C) 2007 British

Ecological Society, Journal of Animal Ecology, 76,

$568-579$ rates were based on habitat parameters measured within the range of each distinct population. We used range boundaries of populations delineated using a 95\% adaptive kernel density estimator where locations of all radio-collared individuals from each distinct population had been pooled (Table 2) (Wittmer et al.
Table 2. Areas used in summarizing covariates at the population and home range scales for mountain caribou in British Columbia, Canada

\begin{tabular}{lclc}
\hline $\begin{array}{l}\text { Population } \\
\text { Purcells-South }\end{array}$ & $\begin{array}{l}\text { Population } \\
\text { range }\left(\mathrm{km}^{2}\right)^{*}\end{array}$ & $\begin{array}{l}\text { Summer } \\
\left(\mathrm{km}^{2}\right)\end{array}$ & $\begin{array}{l}\text { Winter } \\
\left(\mathrm{km}^{2}\right)\end{array}$ \\
\hline $\begin{array}{l}\text { Purcells-Central } \\
\text { Nakusp }\end{array}$ & 2340 & 63 & 53 \\
Duncan & & 53 & 57 \\
Monashee-South & & 46 & 56 \\
Columbia-South & 1761 & 38 & 35 \\
Frisby-Boulder & 613 & 42 & 64 \\
Columbia-North & 4526 & 46 & 89 \\
Kinbasket-South & & 53 & 79 \\
Groundhog & 1277 & 22 & 37 \\
Wells Gray & 8141 & 41 & 87 \\
Allan Creek & & 86 & 200 \\
Barkerville & 742 & 57 & 61 \\
North Cariboo Mtn. & 1779 & 74 & 51 \\
George Mtn. & & 65 & 66 \\
Narrow Lake & & 17 & 92 \\
Hart Ranges & 3890 & 14 & 63 \\
\end{tabular}

*From Wittmer et al. (2005a).

2005a). For each population, we attached covariates associated with the population range.

We initially considered five basic survival models. The first model assumed survival of adult females to be constant over both time and populations $\phi$ (.). The second model assumed time dependency in adult survival $\phi(t)$, while the third considered variation in survival among populations $\phi(\mathrm{g})$. The fourth model considered additive effects between year and population 
573

Landscape changes and decline of caribou
(C) 2007 The Authors. Journal compilation (C) 2007 British Ecological Society, Journal of Animal Ecology, 76, $568-579$ $\phi\left({ }_{t+\mathrm{g}}\right)$, and the fifth model considered an interaction between time and population $\phi\left({ }_{t \times g}\right)$. The fully saturated model $\phi\left({ }_{t \times g}\right)$ executed with a deviance of 0 indicating good model fit. We thus did not adjust ĉ to account for possible model overdispersion (Cooch \& White 2001).

We pooled data from multiple samples resulting in different numbers of females collared over time and population. To eliminate effects due to sampling variance, we therefore decomposed variance components of the best initial model $\phi(\mathrm{g})$ following guidelines described by White, Burnham \& Anderson (2001). Underlying process variance can be estimated in MARK using 'shrunk' estimates $(\tilde{\mathbf{S}})$ where confidence intervals are based on corrected estimates. These corrected estimates ensured that only process variance was included in our survival probabilities.

We then developed a set of 14 a priori candidate models that incorporated the variation in female survival probabilities as a function of the environmental covariates (see Table S1 in Supplementary materials for list of candidate models). Covariates were inspected for collinearity (see Table S2 in Supplementary materials for a list of correlation coefficients) and bivariate correlations were all $\leq 0.75$ within candidate models. We compared models using $\Delta \mathrm{AIC}_{\mathrm{c}}$ (Akaike's Information Criterion corrected for small sample size bias) and considered models within $<4 \mathrm{AIC}_{\mathrm{c}}$ of the top model (Burnham \& Anderson 2002). All covariates were standardized prior to the analysis following guidelines outlined by Cooch \& White (2001). We also performed a principal components analysis (PCA) to attempt and reduce the number of covariates tested. The first two components of the PCA explained 50.73\% and 22.97\% of the variation (see Table S3 in Supplementary materials for loadings of covariates), however, including the first two components as covariates did not improve model fit.

To investigate the relationships among survival probabilities and covariates, we constrained survival probabilities as linear functions of covariates, where the design matrix was linked to the model parameters by the logit link function (White \& Burnham 1999). To directly evaluate the relationship between covariates and real estimates of survival we thus had to back transform covariates as:

$\operatorname{logit} \phi=\alpha_{0}+\beta_{1}\left(X^{\prime}\right)$

eqn 1

and

$\phi=\frac{\exp \left(\alpha_{0}+\beta_{1}\left(X^{\prime}\right)\right)}{1+\exp \left(X^{\prime}\right)}$

eqn 2

where $\alpha_{0}$ is the intercept and $\beta_{1}$ is the slope of the standardized covariate $X^{\prime}$.

\section{Home range scale}

We evaluated whether the likelihood of caribou dying from predation can be explained by factors that vary at the scale of an individuals' home range. Because location sample sizes for some caribou were not sufficient to determine a home range before they died, we did not use animal-specific home range delineations. Instead, we first estimated the mean minimum convex polygon (MCP) home range size for each population using animals that did have sufficient data. Estimates were based on summer (11 June-21 October) or winter (22 October-23 April) seasons, defined using dates that reflect seasonal elevational migrations of mountain caribou in the Columbia Mountains (Apps et al. 2001). For each individual and year, we then calculated the mean positional coordinate for both seasons, regardless of sample size. By splitting the data seasonally, we expected to avoid estimating home range centres that fell within zones of migration between sometimes disjunct winter and summer ranges. Around each estimated seasonal home range centroid, we applied a circular buffer equivalent to the average population-specific home range size (Table 2). We then extracted covariate attributes and averaged them between seasons and among years for each animal. Combining seasonal ranges into multi-annual home ranges in this way was necessary to ensure that our samples were independent. We restricted the number of covariates to the ones that potentially varied among home ranges within populations (i.e. we excluded snow and population density).

Using logistic regression in SAS 9·1, we evaluated whether home range characteristics where individuals had been killed by a predator $(n=59)$ were different from characteristics associated with multi-annual home ranges where individuals had been alive $(n=301)$. Survival was modelled as a linear function of the covariates with the dichotomous dependent variable 'status' (dead or alive). We developed 16 a priori candidate models (see Table S4 in Supplementary materials for list of candidate models) and models were ranked based on AIC. Covariates were again inspected for collinearity (see Table S5 in Supplementary materials for a list of correlation coefficients) and bivariate correlations were all $\leq 0.70$ within candidate models.

\section{Results}

\section{POPULATION SCALE}

Our results strongly support models considering population effects (Table 3 ). Corrected survival estimates of $\phi(\mathrm{g})$ for distinct populations vary between 0.67 in the Purcells-South population and 0.93 in the Hart Ranges population (Table 4). Model fit is improved by including covariates. Specifically, caribou survival generally declines among populations with increasing proportions of early and mid-seral forest stands (FOR1-40, FOR40-100). Higher survival is primarily explained by increasing proportions of old forests (FOR140) and nonforested habitat (NONFOR), and increasing population density (DEN). Models that 
Table 3. Initial models and top models $\left(\Delta \mathrm{AIC}_{\mathrm{c}}<4\right)$ of female survival fitted to data from 10 distinct populations of mountain caribou in British Columbia, Canada; $\beta( \pm \mathrm{SE})$ of standardized covariates, number of model parameters $(\mathrm{k})$, Akaike's information criterion $\left(\mathrm{AIC}_{\mathrm{c}}\right)$ adjusted for small sample size bias, $\mathrm{AIC}_{\mathrm{c}}$ differences $(\Delta), \mathrm{AIC}_{\mathrm{c}}$ weights $(\omega)$ and model deviance (see Table 1 for definition of covariates)

\begin{tabular}{|c|c|c|c|c|c|c|}
\hline Parameters & Intercept $( \pm \mathrm{SE})+\beta( \pm \mathrm{SE})$ & $\mathrm{k}$ & $\mathrm{AIC}_{\mathrm{c}}$ & $\Delta \mathrm{AIC}_{\mathrm{c}}$ & $\mathrm{AIC}_{\mathrm{c}} \omega$ & Deviance \\
\hline \multicolumn{7}{|l|}{ Initial models } \\
\hline$\phi(\mathrm{g})$ & & 10 & $728 \cdot 05$ & $10 \cdot 46$ & $0 \cdot 01$ & $85 \cdot 26$ \\
\hline$\phi()$. & & 1 & $731 \cdot 63$ & $14 \cdot 05$ & $0 \cdot 00$ & $107 \cdot 10$ \\
\hline$\phi\left(g_{\mathrm{g} \times \mathrm{t}}\right)$ & & 55 & $740 \cdot 31$ & $22 \cdot 73$ & $0 \cdot 00$ & $0 \cdot 00$ \\
\hline$\phi\left(\begin{array}{l}\mathrm{t}+\mathrm{g} \\
)\end{array}\right.$ & & 27 & $743 \cdot 50$ & $25 \cdot 91$ & $0 \cdot 00$ & $65 \cdot 13$ \\
\hline$\phi(t)$ & & 19 & $746 \cdot 11$ & $28 \cdot 52$ & $0 \cdot 00$ & $84 \cdot 66$ \\
\hline \multicolumn{7}{|l|}{ Models with covariates } \\
\hline$\phi$ FOR $1-40+$ DEN & $1 \cdot 65(0 \cdot 13)-0 \cdot 40(0 \cdot 12)+0 \cdot 46(0 \cdot 20)$ & 3 & $717 \cdot 59$ & 0 & $0 \cdot 48$ & $89 \cdot 03$ \\
\hline$\phi$ FOR 40-100 & $1 \cdot 63(0 \cdot 10)-0 \cdot 53(0 \cdot 14)$ & 2 & $720 \cdot 20$ & $2 \cdot 61$ & $0 \cdot 13$ & 93.66 \\
\hline$\phi$ FOR $1-40+$ FOR $40-100$ & $1 \cdot 56(0 \cdot 11)-0 \cdot 21(0 \cdot 18)-0 \cdot 35(0 \cdot 20)$ & 3 & $720 \cdot 80$ & $3 \cdot 21$ & $0 \cdot 10$ & $92 \cdot 24$ \\
\hline$\phi$ FOR $140+$ NONFOR & $1 \cdot 57(0 \cdot 10)+0 \cdot 49(0 \cdot 14)+0 \cdot 43(0 \cdot 14)$ & 3 & $721 \cdot 06$ & $3 \cdot 48$ & $0 \cdot 09$ & $92 \cdot 51$ \\
\hline
\end{tabular}

Table 4. Estimates of female adult survival rates of mountain caribou populations in British Columbia, Canada

\begin{tabular}{lll}
\hline Population & $\begin{array}{l}\text { Survival } \\
\text { estimates* }\end{array}$ & $\begin{array}{l}\text { Corrected } \\
\text { survival } \\
\text { estimates } \dagger\end{array}$ \\
\hline Purcells-South & $0 \cdot 55 \pm 0 \cdot 10$ & $0 \cdot 67 \pm 0 \cdot 14$ \\
Nakusp & $0 \cdot 85 \pm 0 \cdot 04$ & $0 \cdot 85 \pm 0 \cdot 04$ \\
Columbia-South & $0 \cdot 85 \pm 0 \cdot 04$ & $0 \cdot 86 \pm 0 \cdot 03$ \\
Frisby-Boulder & $0 \cdot 90 \pm 0 \cdot 10$ & $0 \cdot 90 \pm 0 \cdot 05$ \\
Columbia-North & $0 \cdot 81 \pm 0 \cdot 03$ & $0 \cdot 81 \pm 0 \cdot 03$ \\
Groundhog & $0 \cdot 78 \pm 0 \cdot 10$ & $0 \cdot 79 \pm 0 \cdot 07$ \\
Wells Gray & $0 \cdot 84 \pm 0 \cdot 02$ & $0 \cdot 85 \pm 0 \cdot 02$ \\
Barkerville & $0 \cdot 88 \pm 0 \cdot 06$ & $0 \cdot 88 \pm 0 \cdot 04$ \\
North Cariboo Mtn & $0 \cdot 91 \pm 0 \cdot 04$ & $0 \cdot 90 \pm 0 \cdot 05$ \\
Hart Ranges & $0 \cdot 96 \pm 0 \cdot 03$ & $0 \cdot 93 \pm 0 \cdot 03$ \\
\hline
\end{tabular}

*From Wittmer et al. (2005a).

$\dagger$ Survival estimates corrected for process variation using program MARK.

include habitat amount consistently perform better than models that include habitat configuration.

The four candidate models with $\Delta \mathrm{AIC}_{\mathrm{c}}$ values $<4$ (Table 3), account for 0.80 of the sum of $\mathrm{AIC}_{\mathrm{c}}$ weights. The top ranked model $(\phi$ FOR $1-40+$ DEN) is 3.69 times more likely to be the best model than the second ranked model ( $\phi$ FOR40-100). The best model includes both a negative relationship between caribou survival and proportion of young forests 1-40 years (FOR140) (Fig. 3a) as well as a positive relationship with population density (DEN). Correlation between independent variables in the best model was low (i.e. $0 \cdot 13)$. Despite substantial model selection uncertainty, several effects are consistent across top models. In particular, the proportion of early and mid-seral forest is a main effect in three of the top four models. Of the top models, those that include young forest (FOR1-40) sum to a greater $\mathrm{AIC}_{\mathrm{c}}$ weight $(0 \cdot 58)$ than those that include other covariates.

A post hoc analysis showed that a model constraining survival probabilities only as a function of young forests once the proportion of FOR1-40 increases above a threshold (i.e. $0 \cdot 08,0 \cdot 09$ or $0 \cdot 10$ ) could further improve model fit. In the best threshold model (i.e. $\phi=1 \cdot 91( \pm 0 \cdot 12)-0 \cdot 59( \pm 0 \cdot 17) \times$ FOR $1-40+0 \cdot 42( \pm 0 \cdot 21$ $\left.\times \mathrm{DEN} ; \quad \mathrm{AIC}_{\mathrm{c}}=717 \cdot 38, \Delta \mathrm{AIC}=-0 \cdot 21\right)$, survival is constrained as a function of young forests only in populations where the proportion of FOR1-40 within population ranges exceeds 0.09 (Fig. 3b). Below this threshold, survival is only constrained by population density resulting in estimates of survival probabilities of $0.83,0.87$ and 0.95 when density is kept constant at the minimum, mean and maximum of observed population densities, respectively.

\section{HOME RANGE SCALE}

Our results consistently support models considering the proportion of old forests (Table 5). Top models indicate that caribou are more often killed by predators in home ranges with low old forest (FOR140) composition. Increased vulnerability to predation is also explained by increasing proportions of mid-seral forest stands (FOR40-100 \& FOR100-140) and decreasing proportions of nonforested (NONFOR) habitat. With the exception of FOR140, however, effects of all other covariates in the top model set are questionable because their confidence limits overlap zero. Models that include habitat amount are consistently better supported by the data than those that include habitat configuration.

The six candidate models with $\triangle \mathrm{AIC}$ values $<4$ account for 0.91 of the sum of AIC weights (Table 5). The best model of caribou survival includes a positive relationship with forests aged > 140 years (FOR140) and a negative relationship with forests aged 40-100 years (FOR40-100). The best model, however, performs only 1.26 times better than the second-ranked model that includes only old forests (FOR 140). Despite substantial model selection uncertainty, the proportion of old forests (FOR 140) is included in all six top models (sum AIC weights = 0.91), while mid-aged forest (FOR40100 ) was the second-most predictive variable (sum AIC weights $=0 \cdot 24)$.
Ecology, 76,

$568-579$ 2007 British Ecological Society, Journal of Animal 
575

Landscape changes and decline of caribou (a)

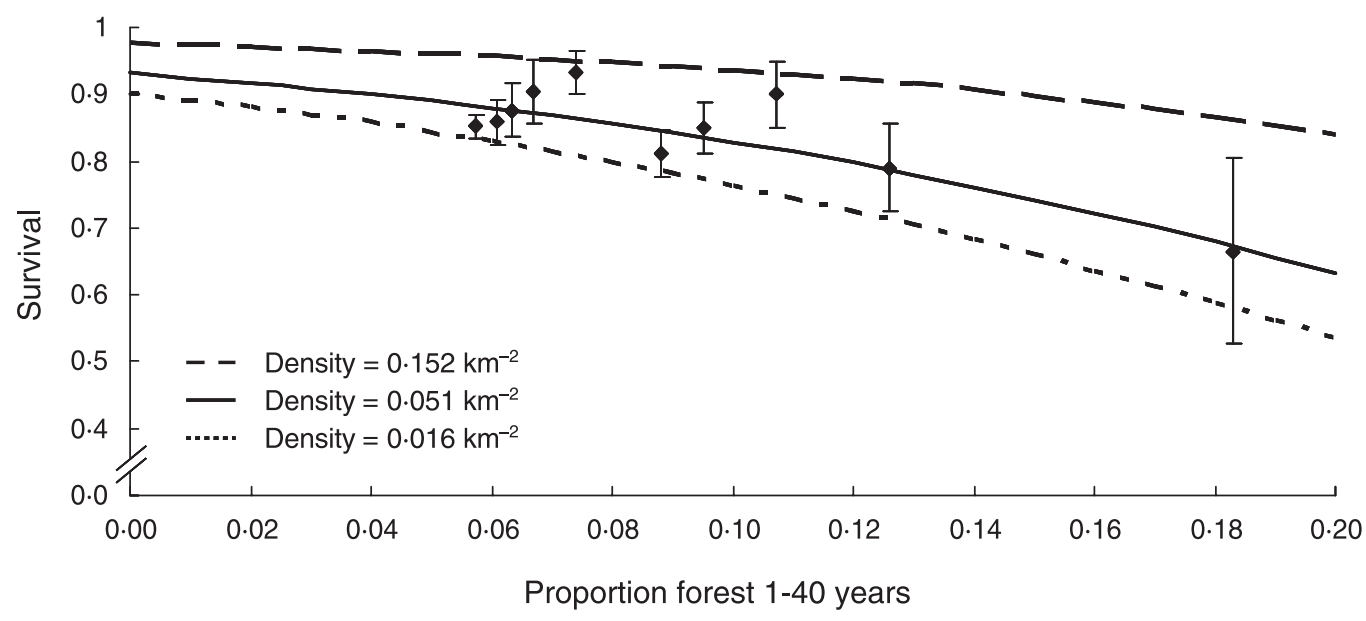

(b)

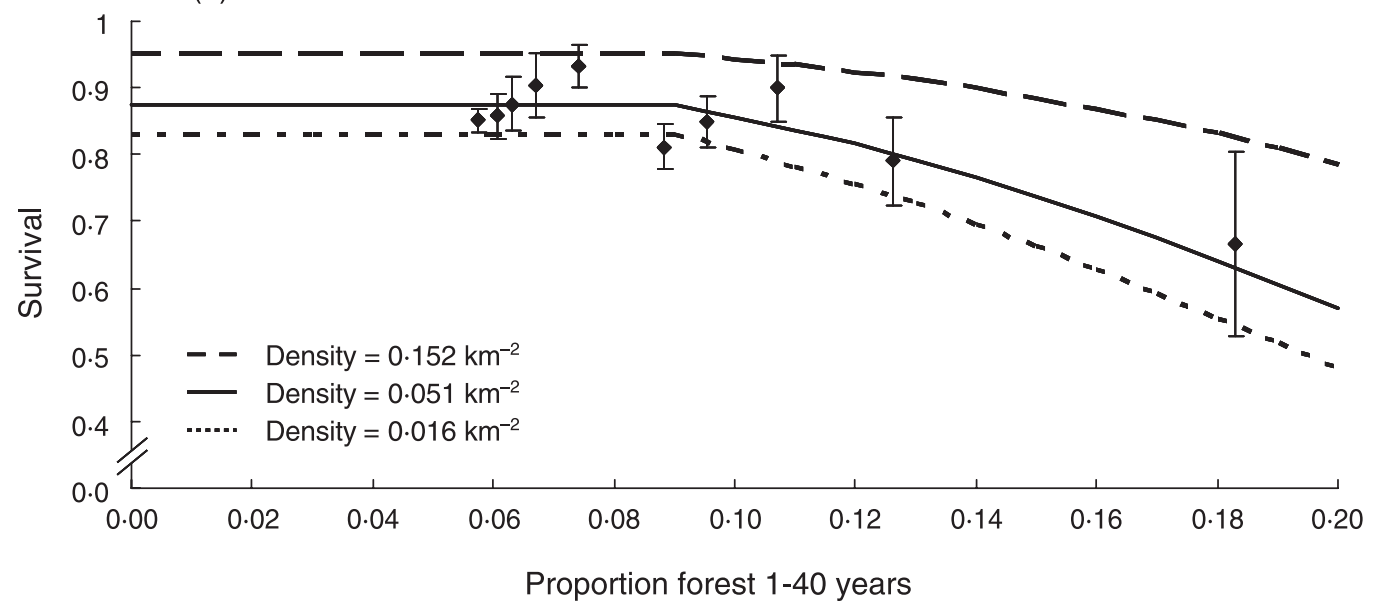

Fig. 3. Correlation between proportion of forest 1-40 years and female adult survival rates of mountain caribou in British Columbia, Canada. The lines indicate goodness-of-fit curves from (a) the best a priori survival model (i.e. $\phi=1 \cdot 65( \pm 0 \cdot 13)-$ $0 \cdot 40( \pm 0 \cdot 12) \times$ FOR $1-40+0 \cdot 46( \pm 0 \cdot 20) \times \mathrm{DEN})$, and (b) the best threshold survival model (i.e. $\phi=1 \cdot 91( \pm 0 \cdot 12)-$ $0 \cdot 59( \pm 0 \cdot 17) \times$ FOR $1-40+0 \cdot 42( \pm 0 \cdot 21) \times \mathrm{DEN})$, back-transformed to real survival estimates using eqns 1 and 2 . Density kept constant at minimum $\left(0.016\right.$ per km²), mean $\left(0.051\right.$ per $\left.\mathrm{km}^{2}\right)$ and maximum $\left(0.152\right.$ per $\left.\mathrm{km}^{2}\right)$ of the observed densities. Data points show population specific survival estimates $( \pm \mathrm{SE})$ corrected for process variation (Table 4$)$.

Table 5. Top models $(\triangle \mathrm{AIC}<4)$ of female caribou dying from predation fitted to data from 338 female mountain caribou in British Columbia, Canada; $\beta$ ( $\pm \mathrm{SE}$ ) of covariates, number of model parameters $(\mathrm{k})$, Akaike's information criterion (AIC), AIC differences $(\Delta)$, and AIC weights $(\omega)$ (see Table 1 for definition of covariates)

\begin{tabular}{llllll}
\hline Model & Intercept $( \pm$ SE $)+\beta( \pm$ SE $)$ & $k$ & AIC & $\Delta$ AIC & AIC $\omega$ \\
\hline FOR140 - FOR40-100 & $0 \cdot 68(0 \cdot 54)-0 \cdot 03(0 \cdot 01)+0 \cdot 03(0 \cdot 02)$ & 3 & $314 \cdot 45$ & $0 \cdot 00$ & $0 \cdot 24$ \\
FOR140 & $0 \cdot 23(0 \cdot 46)-0 \cdot 03(0 \cdot 01)$ & 2 & $314 \cdot 94$ & $0 \cdot 49$ & $0 \cdot 19$ \\
FOR140 - FOR100-140 & $0 \cdot 50(0 \cdot 49)-0 \cdot 03(0 \cdot 01)+0 \cdot 04(0 \cdot 03)$ & 3 & $315 \cdot 05$ & $0 \cdot 59$ & $0 \cdot 18$ \\
FOR140 + NONFOR & $0 \cdot 50(0 \cdot 72)-0 \cdot 04(0 \cdot 01)-0 \cdot 01(0 \cdot 01)$ & 3 & $315 \cdot 37$ & $0 \cdot 91$ & $0 \cdot 15$ \\
FOR140 + MPS140 & $0 \cdot 24(0 \cdot 46)-0 \cdot 03(0 \cdot 01)-0 \cdot 00(0 \cdot 16)$ & 3 & $316 \cdot 77$ & $2 \cdot 32$ & $0 \cdot 08$ \\
FOR140 + FOR1-40 & $0 \cdot 23(0 \cdot 47)-0 \cdot 03(0 \cdot 01)-0 \cdot 00(0 \cdot 02)$ & 3 & $316 \cdot 94$ & $2 \cdot 49$ & $0 \cdot 07$ \\
\hline
\end{tabular}

(C) 2007 The Authors. Journal compilation (C) 2007 British

Ecological Society, Journal of Animal Ecology, 76,

568-579

\section{Discussion}

Our objective was to examine the importance of several environmental variables at two spatial scales that may affect vital rates and thus precipitate population declines of a threatened large herbivore. We focused our analyses on factors influencing adult female survival because variation in rates of decline among caribou populations was best explained by differences in this parameter (Wittmer et al. 2005a). At both spatial scales, forest age class distribution was the best predictor of adult female survival.

At the population scale, variation in adult survival was influenced by the proportion of early and mid-seral 
H. U. Wittmer et al. forests within population ranges with survival being lower where younger forests are more common. This result is consistent with the conclusions of Wittmer et al. (2005b) who found the proximate cause of mountain caribou decline to be predation in the form of apparent competition rather than food regulation or predation-sensitive foraging. Forests in early seral stages due to recent timber harvest or wildfire are preferred habitat for alternate ungulate prey such as moose (Schwartz \& Franzmann 1991; Rempel et al. 1997) that have expanded in distribution and number over the past several decades in our study area (Spalding 1990). Similarly, white-tailed deer populations may also increase following anthropogenic habitat modifications (Roseberry \& Woolf 1998) and have recently expanded their distribution within our study area (Shackleton 1999). Forests in mid-seral stages do not support ideal habitat conditions for either caribou or alternate prey species. However, higher proportions of these forests reflect drier portions of our study area with a relatively frequent fire history across the broader ecosystem and more abundant alternative prey and predators over longer periods of time. Because the amount of early and mid-seral forests within population ranges were highly correlated, it is difficult to clearly differentiate between their respective effects.

At the home range scale, caribou were more likely to be killed by predators if they had a relatively small proportion of old forest in their range. This result supports suggestions by James \& Stuart-Smith (2000) that caribou population declines may be precipitated by increased predator abundance and efficiency following a reduction and fragmentation of older forests due to forest harvesting or wildfire as well as increased roading in conjunction with forest harvesting. This result also suggests that resource selection at small spatial scales may influence fitness of individual caribou (McLoughlin, Dunford \& Boutin 2005).

Conducting similar analyses but at different spatial scales may provide opposing results and suggest the influence of different mechanisms (Wiens 1989). In the case of mountain caribou, however, features affecting their persistence remain similar across scales. These caribou currently persist in the portion of their historic distribution with wetter climatic conditions with relatively deep snow, infrequent fire history and consequently, more old and less mid-seral forests than where they have been extirpated (Apps \& McLellan 2006). Accordingly, we found that adult female survival was lowest in populations associated with a higher proportion of young and mid-seral forests. At the home range scale, females were killed by predators more frequently in landscapes with relatively low old forest composition. These results suggest that without additional management of predators and alternative prey, mountain caribou populations can only remain viable in landscapes where early seral forests are rare and where old forests are common in their home ranges.

Our analysis has also evaluated the relative influence of landscape patterns vs. overall habitat amount (Boutin \& Hebert 2002). At both spatial scales, we found greater support for variables reflecting habitat amount than habitat configuration. This result is consistent with other studies that compared relative effects of these factors (Fahrig 2003) and is expected in landscapes with high proportions of suitable habitat (Andren 1994). Although forest managers often focus on minimizing habitat fragmentation, our results suggest that overall habitat amount is more important to adult female survival at broader scales. At finer spatial scales, however, the distribution of old forest edge may influence caribou vulnerability to some predators (Apps et al. 2006).

Survival rates can be influenced by the age structure of the population, both in the absence of predators and where predation is a significant cause of mortality (e.g. Gaillard et al. 2000; Festa-Bianchet, Gaillard \& Cote 2003). Variation in age structure among populations of mountain caribou may thus have contributed to the observed variation in survival among populations. We were unable to test the effect of age because accurate estimates were unavailable for the living sample.

Of particular importance to conservation, we found an additive effect between early seral forest stands and population density. At low population densities, caribou had lower survival probabilities in areas with greater amounts of young forests. The additive effect between low population density and young forests suggests that caribou are vulnerable to predation and continued population decline even at very low densities. This result supports the prediction of Wittmer et al. (2005b) (based on the same data set), that caribou population declines are likely to continue even as populations reach very low densities because caribou have become secondary prey to predators whose populations are responding to increasing alternate ungulate prey species. In such a system, the secondary prey species may be extirpated where they fail to spatially or temporally separate themselves from alternate prey species and their predators (Holt \& Lawton 1994; Roemer, Donlan $\&$ Courchamp 2002). The apparent resilience of caribou survival when the proportion of young forests within population ranges is at very low levels further suggests that changes in the predator-prey system may occur at a specific threshold. Such a threshold may be explained by a population response from other ungulate species and their predators, resulting in unsustainable predation on caribou.

Predation strongly influences ungulate population dynamics (e.g. Messier 1991; Sinclair, Mduma \& Brashares 2003; Owen-Smith, Mason \& Ogutu 2005) particularly when the relative availability of prey species changes. Increasingly, the observed extinction processes of many species have been linked to anthropogenic changes in species composition, particularly following the introduction of exotics (Sinclair et al. 1998; Roemer et al. 2002). Asymmetric predation by means of apparent competition, where predators are
Ecology, 76,

568-579 (C) 2007 British Ecological Society, Journal of Animal 
577

Landscape changes and decline of

caribou maintained by the more common, often exotic alternative prey, has been identified as the underlying mechanism causing the decline and extinction of native species. The importance of apparent competition resulting from shifts in the abundance and distribution of native species following anthropogenic habitat modifications and possibly climate change in the absence of exotic species has largely been overlooked (but see Sweitzer, Jenkins \& Berger 1997; Robinson, Wielgus \& Gwilliam 2002). Caribou in this study are part of a complex multipredator, multiprey system where the distribution and abundance of alternative ungulate prey populations have increased in response to habitat modifications and likely climate change (Spalding 1990; Shackleton 1999). Our results suggest that even without the introduction of exotics, apparent competition can cause rapid population declines and extirpation where prey availability has increased. Conserving a species that is in rapid decline and nearing extinction due to apparent competition in a system of indigenous species is a significant challenge for managers (Courchamp, Woodroffe \& Roemer 2003). Management options required to maintain such a species include continuous predator management or a temporary reduction of predators combined with a continuous reduction in their primary prey either by hunting or by allowing vegetative conditions to gradually return to where they are less favourable to the primary prey.

\section{Acknowledgements}

This project was funded by the British Columbia Ministries of Forests and Environment, Columbia Basin Fish and Wildlife Compensation Program, Parks Canada, Forest Renewal British Columbia, and numerous forestry companies that operate across the range of mountain caribou in British Columbia. H.U.W. was supported by fellowships from the International Council for Canadian Studies, the University of British Columbia, and the Faculty of Agricultural Sciences at the University of British Columbia. Additional caribou telemetry data were kindly provided by D. Seip, T. Kinley, D. Hamilton, J. Young and G. Watts. We also thank J. Boulanger and Y. Richard for discussions about survival analyses using program MARK. P. Arcese, D. Armstrong, D. Shackleton, an anonymous referee and in particular J.-M. Gaillard provided many helpful comments on earlier versions of this manuscript.

\section{References}

Andren, H. (1994) Effects of habitat fragmentation on birds and mammals in landscapes with different proportions of suitable habitat - a review. Oikos, 71, 355-366.

(C) 2007 The Authors Journal compilation (C) 2007 British Ecological Society, Journal of Animal Ecology, 76, $568-579$
Columbia Mountains, British Columbia. Journal of Wildlife Management, 65, 65-77.

Apps, C.D., McLellan, B.N., Serrouya, R. \& Wittmer, H.U. (2006) Spatial factors influencing the mortality risk of mountain caribou. Research Branch, Ministry of Forests, Revelstoke, British Columbia. Unpublished Manuscript.

Ballard, W.B., Krausman, P.R., Boe, S., Cunningham, S. \& Whitlaw, H.A. (2000) Short-term response of gray wolves, Canis lupus, to wildfire in northwestern Alaska. Canadian Field Naturalist, 114, 241-247.

Berger, J. (2004) The last mile: how to sustain long-distance migration in mammals. Conservation Biology, 18, 320 331.

Bergerud, A.T. \& Elliot, J.P. (1986) Dynamics of caribou and wolves in northern British Columbia. Canadian Journal of Zoology, 64, 1515-1519.

Boutin, S. \& Hebert, D. (2002) Landscape ecology and forest management: developing an effective partnership. Ecological Applications, 12, 390-397.

Burnham, K.P. \& Anderson, D.R. (2002) Model Selection and Multimodel Inference: a Practical Information-Theoretic Approach. Springer-Verlag, New York.

Carroll, C., Noss, R.F. \& Paquet, P.C. (2001) Carnivores as focal species for conservation planning in the Rocky Mountain region. Ecological Applications, 11, 961-980.

Caughley, G. (1994) Directions in conservation biology. Journal of Animal Ecology, 63, 214-244.

Cooch, E.G. \& White, G. (2001) Using MARK - a gentle introduction. http://canuck.dnr.cornell.edu/mark/ (accessed April 2005).

COSEWIC (2002) COSEWIC Assessment and Update Status Report on the Woodland Caribou Rangifer tarandus Caribou. Canada Committee on the Status of Endangered Wildlife in Canada, Ottawa, ON.

Coulson, T., Albon, S.D., Pilkington, J. \& Clutton-Brock, T.H. (1999) Small-scale spatial dynamics in a fluctuating ungulate population. Journal of Animal Ecology, 68, $658-671$.

Courchamp, F., Woodroffe, R. \& Roemer, G. (2003) Removing protected populations to save endangered species. Science, 302, 1532.

Fahrig, L. (2003) Effects of habitat fragmentation on biodiversity. Annual Reviews in Ecology and Systematics, 34, 487515.

Festa-Bianchet, M., Gaillard, J.M. \& Cote, S.D. (2003) Variable age structure and apparent density dependence in survival of adult ungulates. Journal of Animal Ecology, 72, 640-649.

Franklin, A.B., Anderson, D.R., Gutierrez, R.J. \& Burnham, K.P. (2000) Climate, habitat quality, and fitness in northern spotted owl populations in northwestern California. Ecological Monographs, 70, 539-590.

Gaillard, J.-M., Festa-Bianchet, M., Yoccoz, N.G., Loison, A. $\&$ Toïgo, C. (2000) Temporal variation in fitness components and population dynamics of large herbivores. Annual Reviews in Ecology and Systematics, 31, 367-393.

Goward, T. (1998) Observations on the ecology of the lichen genus Bryoria in high elevation conifer forests. Canadian Field Naturalist, 112, 496-501.

Holt, R.D. \& Lawton, J.H. (1994) The ecological consequences of shared natural enemies. Annual Reviews in Ecology and Systematics, 25, 495-520.

James, A.R.C. \& Stuart-Smith, A.K. (2000) Distribution of caribou and wolves in relation to linear corridors. Journal of Wildlife Management, 64, 154-159.

McLoughlin, P.D., Dunford, J.S. \& Boutin, S. (2005) Relating predation mortality to broad-scale habitat selection. Journal of Animal Ecology, 74, 701-707.

Meidinger, D.V. \& Pojar, J. (1991) Ecosystems of British Columbia. Special Report Series 4. Ministry of Forests, Victoria, BC. 
H. U. Wittmer et al.
Messier, F. (1991) The significance of limiting and regulating Journal of Animal Ecology, 60, 377-393.

Ministry of Sustainable Resource Management (2004) Snow data archives. http://srmhttp://www.gov.bc.ca/aib/wat/rfc/ (accessed April 2005).

Noon, B.A. \& Blakesley, J.A. (2006) Conservation of the Northern Spotted Owl under the Northwest Forest Plan. Conservation Biology, 20, 288-296.

Owen-Smith, N., Mason, D.R. \& Ogutu, J.O. (2005) Correlates of survival rates for 10 African ungulate populations: density, rainfall and predation. Journal of Animal Ecology, 74, 774-788.

Pettorelli, N., Gaillard, J.M., Yoccoz, N.G., Duncan, P., Maillard, D., Delorme, D., Van Laere, G. \& Toïgo, C. (2005) The response of fawn survival to changes in habitat quality varies according to cohort quality and spatial scale. Journal of Animal Ecology, 74, 972-981.

Pollock, K.H., Winterstein, S.R., Bunck, C.M. \& Curtis, P.D. (1989) Survival analysis in telemetry studies: the staggered entry design. Journal of Wildlife Management, 53, 7-15.

Rempel, R.S., Elkie, P.C., Rodgers, A.R. \& Gluck, M.J. (1997) Timber management and natural-disturbance effects on moose habitat: landscape evaluation. Journal of Wildlife Management, 61, 517-524.

Resource Inventory Branch (1995) Relational Data Dictionary $(R D D), 2.0$. Ministry of Forests, Victoria, BC.

Rettie, W.J. \& Messier, F. (1998) Dynamics of woodland caribou populations at the southern limit of their range in Saskatchewan. Canadian Journal of Zoology, 76, 251259.

Robinson, H.S., Wielgus, R.B. \& Gwilliam, J.C. (2002) Cougar predation and population growth of sympatric mule deer and white-tailed deer. Canadian Journal of Zoology, 80, 556-568.

Roemer, G.W., Donlan, C.J. \& Courchamp, F. (2002) Golden eagles, feral pigs, and insular carnivores: How exotic species turn native predators into prey. Proceedings of the National Academy of Sciences USA, 99, 791-796. habitat of woodland caribou, Selkirk Mountains, British Columbia. Journal of Wildlife Management, 53, 238243.

Rominger, E.M., Robins, C.T. \& Evans, M.A. (1996) Winter foraging ecology of woodland caribou in northeastern Washington. Journal of Wildlife Management, 60, 719-728.

Roseberry, J.L. \& Woolf, V. (1998) Habitat - population density relationships for white-tailed deer in Illinois. Wildlife Society Bulletin, 26, 252-258.

Rotenberry, J.T. \& Wiens, J.A. (1991) Weather and reproductive variation in shrubsteppe sparrows: a hierarchical analysis. Ecology, 72, 161-166.

Schaefer, J.A. (2003) Long-term range recession and the persistence of caribou in the Taiga. Conservation Biology, 17, 1435-1439.

Schwartz, C.C. \& Franzmann, A.W. (1991) Interrelationship of black bears to moose and forest succession in the northern coniferous forest. Wildlife Monographs, 113, 158.

Seip, D.R. (1992) Factors limiting woodland caribou populations and their interrelationships with wolves and moose in southeastern British Columbia. Canadian Journal of Zoology, 70, 1494-1503.

(C) 2007 The Authors. Journal compilation (C) 2007 British Ecological Society, Journal of Animal Ecology, 76,

568-579 Royal British Columbia Museum and University of British Columbia Press, Vancouver, BC.

Sih, A., Jonsson, B.G. \& Luikart, G. (2000) Habitat loss: ecological, evolutionary and genetic consequences. Trends in Ecology and Evolution, 15, 132-134.

Sinclair, A.R.E., Pech, R.P., Dickman, C.R., Hik, D., Mahon, factors on the demography of moose and white-tailed deer.

Rominger, E.M. \& Oldemeyer, J.L. (1989) Early-winter

on conservation of endangered prey. Conservation Biology, 12, 564-575.

Sinclair, A.R.E., Mduma, S. \& Brashares, J.S. (2003) Patterns of predation in a diverse predator-prey system. Nature, $\mathbf{4 2 5}$, 288-290.

Spalding, D.J. (1990) The Early History of Moose (Alces alces): Distribution and Relative Abundance in British Columbia. Contributions to Natural Science Number 11. Royal British. Columbia Museum, Victoria, BC.

Stuart-Smith, A.K., Bradshaw, C.J.A., Boutin, S., Herbert, D.M. \& Rippin, A.B. (1997) Woodland caribou relative to landscape patterns in northeastern Alberta. Journal of Wildlife Management, 61, 622-633.

Sweitzer, R.A., Jenkins, S.H. \& Berger, J. (1997) Nearextinction of porcupines by mountain lions and consequences of ecosystem change in the Great Basin Desert. Conservation Biology, 11, 1407-1417.

Terry, E.L., McLellan, B.N. \& Watts, G.S. (2000) Winter habitat ecology of mountain caribou in relation to forest management. Journal of Applied Ecology, 37, 589602.

US Fish and Wildlife Service (1994) Recovery Plan for Woodland Caribou in the Selkirk Mountains. US Fish and Wildlife Service, Portland, OR.

White, G.C. \& Burnham, K.P. (1999) Program MARK: survival estimation from populations of marked animals. Bird Study, 46, S120-S139.

White, G.C., Burnham, K.P. \& Anderson, D.R. (2001) Advanced features of Program Mark. Wildlife, Land, and People: Priorities for the 21 st Century. Proceedings of the Second International Wildife Management Congress (eds R. Field, R.J. Warren, H. Okarma \& P.R. Sievert), pp. 368-377. The Wildlife Society, Bethesda, Maryland, USA.

Wiens, J.A. (1989) Spatial scaling in ecology. Functional Ecology, 3, 385-397.

Wittmer, H.U., McLellan, B.N., Seip, D.R., Young, J.A., Kinley, T.A., Watts, G.S. \& Hamilton, D. (2005a) Population dynamics of the endangered mountain ecotype of woodland caribou (Rangifer tarandus caribou) in British Columbia, Canada. Canadian Journal of Zoology, 83, 407418.

Wittmer, H.U., Sinclair, A.R.E. \& McLellan, B.N. (2005b) The role of predation in the decline and extirpation of woodland caribou. Oecologia, 144, 257-267.

Zar, J.H. (1999) Biostatistical Analysis, 4th edn. Prentice Hall, Upper Saddle River, NJ.

Received 12 October 2006; accepted 26 January 2007

\section{Supplementary material}

The following supplementary material is available for this article.

Table S1. List of a priori candidate models at the population scale used to evaluate the importance of covariates for survival of female mountain caribou in British Columbia, Canada.

TableS2. Correlation coefficients of covariates used to model survival probabilities of adult female mountain caribou in British Columbia, Canada. P. \& Newsome, A.E. (1998) Predicting effects of predation
Table S3. Loadings of first and second principal components based on parameters measured within 10 distinct population ranges of mountain caribou in British Columbia, Canada. 
Landscape changes

and decline of

caribou
Table S4. List of a priori candidate models at the home range scale used to evaluate the importance of habitat covariates on the probability that caribou were killed by predation.

Table S5. Correlation coefficients of habitat covariates used to model probabilities of caribou dying from predation.
This material is available as part of the online article from: http://www.blackwell-synergy.com/doi/full/10.1111/ j.1365-2656.2007.01220.x

Please note: Blackwell Publishing is not responsible for the content or functionality of any supplementary materials supplied by the authors. Any queries (other than missing material) should be directed to the corresponding author for the article. 